\title{
Preliminary Clinical Outcomes after Implantation of Newer-Generation Biodegradable Polymer-Coated Everolimus-Eluting Stent in "Real-World" Patients with Coronary Artery Disease
}

\author{
Manjinder Singh Sandhu1, Harish Sanadhya², Shailendra Trivedi³, Paramu Mangalanandan4, \\ Rashmit Pandya5, Asif Raheem6, Vineet Malik7 , Bharat Chanana7 \\ ${ }^{1}$ Department of Cardiology, Artemis Hospital, Gurgaon, India \\ ${ }^{2}$ Department of Cardiology, Geetanjali Medical College \& Hospital, Udaipur, India \\ ${ }^{3}$ Department of Cardiology, Medanta Super Speciality Hospital, Indore, India \\ ${ }^{4}$ Department of Cardiology, Cosmopolitan Hospital, Thiruvananthapuram, India \\ ${ }^{5}$ Department of Cardiology, Lifecare Institute of Medical Sciences \& Research, Ahmedabad, India \\ ${ }^{6}$ Department of Cardiology, Yashfeen Cardiac Hospital, Navsari, India \\ ${ }^{7}$ Department of Cardiology, Maharaja Agrasen Hospital, Delhi, India \\ Email: sandhums@gmail.com
}

How to cite this paper: Sandhu, M.S., Sanadhya, H., Trivedi, S., Mangalanandan, P., Pandya, R., Raheem, A., Malik, V. and Chanana, B. (2016) Preliminary Clinical Outcomes after Implantation of Newer-Generation Biodegradable Polymer-Coated Everolimus-Eluting Stent in "Real-World" Patients with Coronary Artery Disease. World Journal of Cardiovascular Diseases, 6, 468-476. http://dx.doi.org/10.4236/wjcd.2016.612050

Received: October 16, 2016

Accepted: December 25, 2016

Published: December 28, 2016

Copyright $\odot 2016$ by authors and Scientific Research Publishing Inc. This work is licensed under the Creative Commons Attribution International License (CC BY 4.0).

http://creativecommons.org/licenses/by/4.0/ (c) (i)

Open Access

\begin{abstract}
Background and Objective: In the contemporary practice, the use of drug-eluting stents is still associated with low mortality benefits, restenosis and stent thrombosis. To address these issues, newer generation, thin-strut, biodegradable polymer coated stents has been designed. Thus, the aim of the study is to assess the safety and clinical performance of the Everoflex (Sahajanand Medical Technologies Pvt. Ltd., Surat, India), a newer generation biodegradable polymer coated everolimus-eluting stent, in unselected "real-world" patients with coronary artery disease. Methods: It is a multicentre, retrospective, non-randomized, single-arm study enrolling all the consecutive patients who underwent implantation with the Everoflex for coronary artery disease from April 2014 to March 2016. The primary end-point of the study is 30day major adverse cardiovascular events (MACE) rate, which consists of cardiac death, myocardial infarction, target lesion revascularization and target vessel revascularization. Stent thrombosis was also analyzed and reported. Results: A total of 340 patients were intervened successfully with 395 everolimus eluting stents $(1.3 \pm 0.6$ stents per patient). Out of total patients $(58.7 \pm 10.5$ years), $77.9 \%$ were male and comorbidities like diabetes and hypertension were observed in $31.2 \%$ and $35.3 \%$ pa-
\end{abstract}


tients, respectively. According to ACC/AHA classification, there were $34.4 \%$ type B lesions and $53.2 \%$ type $\mathrm{C}$ lesions, indicating a higher proportion of complexity involved. Moreover, $57.9 \%$ patients had multivessel disease and there were $15.4 \%$ total occlusions. At 30 days, follow-up was completed in $100 \%$ patients. The MACE was found to be $1.5 \%$, which is a composite of $1.2 \%$ cardiac death and $0.3 \%$ target lesion revascularization. Stent thrombosis at 30 days was found to be $0.3 \%$. Conclusion: The low incidence of MACE and stent thrombosis clearly depicts excellent safety and clinical performance of the Everoflex in unselected real world patients with coronary artery disease.

\section{Keywords}

Drug-Eluting Stents, Everolimus, Biodegradable Polymer, Treatment Outcome

\section{Introduction}

The approach of percutaneous coronary intervention, since its advent, has been most promising for the treatment of coronary artery disease. To be specific, metallic coronary stents coated with potent immunosuppressive agents have dramatically reduced neointimal hyperplasia and consequently restenosis as compared to bare metal stents [1] [2]. But the older generation drug-eluting stents while reducing in-stent restenosis have conversely increased the rate of stent thrombosis [3] [4]. Addressing some of the clinical issues, associated problems like inflammation induced by polymers, thicker stent struts and action of antiproliferative agents, triggered the attempts to develop newer-generation thinner strut stents with better polymer and elution dynamics. One of such potential attempt resulted in development of the Everoflex (Sahajanand Medical Technologies Pvt. Ltd. Surat, Gujarat, India). It is biodegradable polymer coated everolimus-eluting stent with cobalt chromium stent platform and stent architecture as thin as $60 \mu$. Drug-eluting stents, especially everolimus-eluting stents, are believed to reduce both in-stent restenosis as well as stent thrombosis [5] [6] [7]. However, there are several discrepancies regarding the effectiveness of everolimus-eluting stents compared to other limus-eluting stents, like sirolimus, biolimus and zotarolimus-eluting stents. Two of the major comparative analysis have demonstrated that everolimus is non-inferior to sirolimus in overall reduction of repeat revascularization and definite ST [8] [9]. On the contrary, stratified analysis by Barber et al. observed significant reduction in overall clinical events in comparison to paclitaxel-eluting stents, intermediate in comparison to zotarolimus-eluting stents and slightest against sirolimus-eluting stents. Thus, the aim of this study is to evaluate safety and clinical performance of Everoflex everolimuseluting stents in unselected "real-world" patients with coronary artery disease.

\section{Methods}

\subsection{Study Design}

It is a retrospective, observational, non-randomized multicentre on-going study being 
carried out at 8 different sites across India. It enrolled patients, who underwent implantation with Everoflex stents for coronary artery disease from April 2014 to March 2016. The study strictly adhered to the principles of Good Clinical Practice and Declaration of Helsinki. Written informed consent was obtained from all the patients and the study was approved by the institutional ethics committee.

\subsection{Patient Selection}

All the patients with age greater than or equal to 18 years and undergoing implantation with Everoflex everolimus-eluting coronary stent system were included in the study. The only exclusion criterion was refusal to give informed consent from the patient.

\subsection{Description of the Study Stent}

Everoflex is a combination product comprising of two regulated components: 1) a device-It is made up of Flexinnium coronary stent system (Sahajanand Medical Technologies Pvt. Ltd. Surat, Gujarat, India) as its platform. Flexinnium stent comprise of medical grade L605 cobalt chromium (Co-Cr) alloy having strut thickness of $60 \mu$; 2) a drug product-The drug, at the concentration of $1.0 \mu \mathrm{g} / \mathrm{mm}^{2}$, along with polymeric matrix is coated on the conformal surface of the stent. The polymeric matrix consists of poly-L-lactide, poly L-lactide-co-caprolactone and polyvinyl pyrrolidone to control the drug elution from stent coating. The average coating thickness of the stent is between 3 - $4 \mu \mathrm{m}$ and it releases approximately $80 \%$ of drug within first 28 days. Figure 1 represents in-vitro percentage cumulative drug release profile of the Everoflex stent in biological media. After releasing the drug, biodegradable polymers undergo hydrolysis and then gradually degrade into biologically acceptable molecules that are metabolized and removed from the body via normal metabolic pathways. Scanning electron microscopy images of sterile crimped stents and expanded stents are depicted in Figure 2 showing a smooth and uniform coating surface with minimal-to-no structural defects such as webbing, bridging, and strut-to-strut contact, even after expansion of the stent.

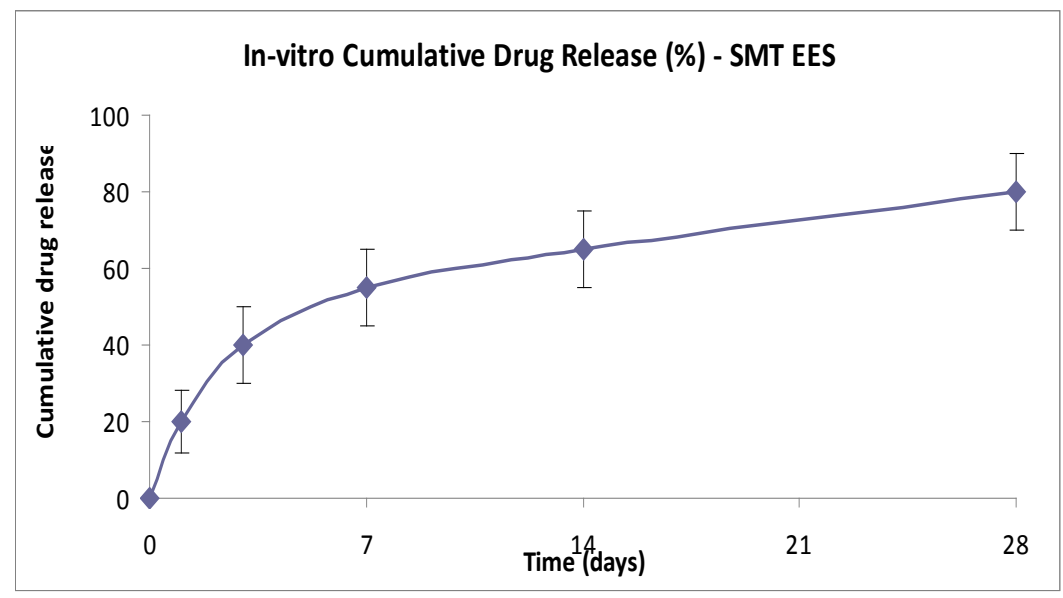

Figure 1. In-vitro percentage cumulative drug release profile of the Everoflex stent in biological media. 


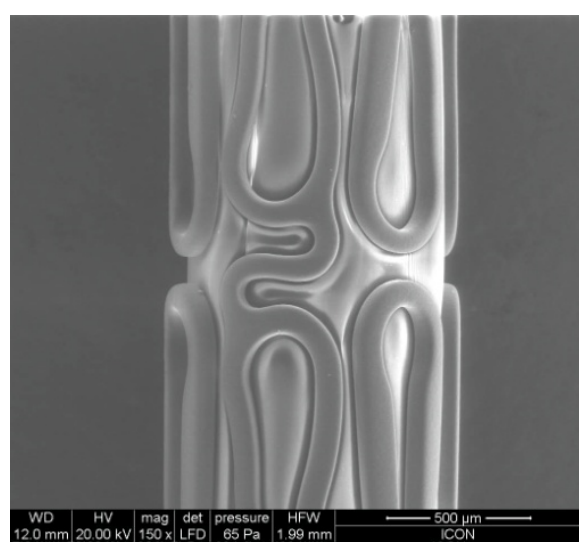

(a)

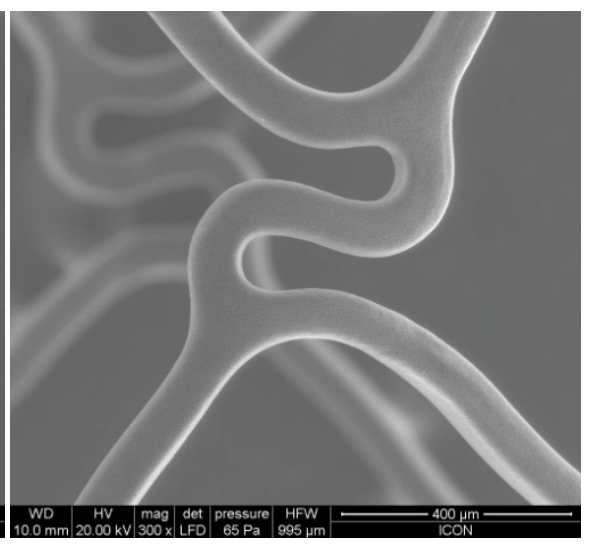

(b)

Figure 2. Scanning electron microscopy images of sterile (a) crimped stents and (b) expanded stents.

\subsection{Coronary Intervention Procedures and Adjuvant Medications}

Coronary interventional procedures and adjuvant medications were performed according to standard guidelines [10]. All patients received dual antiplatelet therapy (DAPT) including a loading dose of aspirin $(300 \mathrm{mg})$ and clopidogrel $(600 \mathrm{mg})$ or prasugrel $(60 \mathrm{mg}$ ) or ticagrelor (two tablets of $90 \mathrm{mg}$ each). The procedural anticoagulation was achieved either with heparin or with bivalirudin. However, the intraprocedural administration of glycoprotein IIb/IIIa inhibitor was at the investigator's discretion. All patients were advised to maintain DAPT (aspirin: 75 - $300 \mathrm{mg}$ daily indefinitely and clopidogrel: $75 \mathrm{mg}$ daily or prasugrel: $10 \mathrm{mg}$ daily or ticagrelor: $90 \mathrm{mg}$ twice daily for at least 12 months) after the procedure.

\subsection{Study Endpoints and Their Definitions}

The primary endpoint was major adverse cardiac events (MACE), which is a composite of cardiac death, myocardial infarction (MI), target lesion revascularization (TLR) and target vessel revascularization (TVR) at 30-days follow-up. Stent thrombosis (ST), as defined according to Academic Research Consortium (ARC) was also analyzed [11].

Any death due to undetermined cause was reported as cardiac death. Q-wave MI was considered, when there was development of new Q-wave of more than 0.04 seconds in two or more adjoining leads along with increase in cardiac markers like Troponin I or $\mathrm{T}$, creatine kinase or MB isoform. Non Q-wave MI was considered when there was more than three times elevation in creatinine kinase levels along with elevation in $\mathrm{MB}$ isoform and Troponin markers $\mathrm{T}$ or I without development of new Q-waves. Target lesion revascularization was considered when there was stenosis in treated segment (5 $\mathrm{mm}$ proximal and $5 \mathrm{~mm}$ distal edges). Target vessel revascularization was considered when there was stenosis in any segment of the treated vessel and had to undergo revascularization with either PCI or coronary artery by-pass grafting (CABG). Stent thrombosis (ST) was considered acute when it occurred within 24 hours, sub-acute when it occurred between 1 and 30 days, and late when it occurred after 30days. The "definite" 
stent thrombosis was counted when it was detected angiographically. If the patient had a target vessel-related MI or died of a coronary event, it was "probable", and "possible" if any unexplained death occurred from 30 days after intracoronary stenting.

\subsection{Follow-Up}

Patients were followed-up at 30-days ( \pm 7 days window period) by telephonic conversation. Long term follow-up is planned at six-months, one-year and then every year upto five-years. Follow-up data relating to current clinical status, prior hospitalization and occurrence of any of the aforementioned adverse events were collected.

\subsection{Statistical Analysis}

Continuous variables are presented as mean \pm standard deviation and categorical variables are presented as counts and percentages. All data were analysed using the Statistical Package for Social Sciences (SPSS; Chicago, IL, USA) program, version 15.

\section{Results}

\subsection{Baseline Demographics and Clinical Characteristics}

A total of 340 patients $(58.7 \pm 10.5$ years), who successfully underwent intervention with the Everoflex everolimus-eluting coronary stent system, were enrolled in the study. Out of 340 patients, 265 (77.9\%) were male indicating their predominance. Comorbidities like hypertension and diabetes mellitus were observed in 120 (35.3\%) and 106 (31.2\%) patients, respectively. Detailed risk factors, cardiac history of enrolled patients and clinical presentation are outlined in Table 1.

\subsection{Lesion and Procedural Characteristics}

A total of 395 lesions were intervened successfully with 447 stents having an average stent length and diameter of $26.9 \pm 9.4 \mathrm{~mm}$ and $2.9 \pm 0.3 \mathrm{~mm}$, respectively. According to ACC/AHA classification, there were 210 (53.2\%) and 136 (34.4\%) type C and type B lesions, respectively. There were 197 (57.9\%) multivesssel diseases and 61 (15.4\%) total occlusion. This clearly indicates complex and high-risk patient involvement. Lesion and procedural characteristics are described in Table 2.

\subsection{Clinical Outcomes}

The acute and preliminary result at 30-days follow-up demonstrated MACE rate of 5 (1.5\%), which constituted $4(1.2 \%)$ cardiac death and $1(0.3 \%)$ target lesion revascularization. The clinical outcomes at 30-days are shown in Table 3.

\section{Discussion}

Everolimus, although believed to have less affinity for its receptor FKBP12, it has shown similar or better efficacy, as compared to other limus-eluting stents, to inhibit smooth muscle proliferation [12]. It is slightly more lipophilic as compared to its analogue, sirolimus. It readily gets absorbed in the arterial walls and gets stored in the fatty 
Table 1. Baseline demographics and clinical characteristics.

\begin{tabular}{|c|c|}
\hline Characteristics & $\mathrm{n}=340$ patients \\
\hline \multicolumn{2}{|c|}{ Demographic characteristics } \\
\hline Age, years $($ mean $\pm S D)$ & $58.7 \pm 10.5$ \\
\hline Male, n (\%) & $265(77.9 \%)$ \\
\hline \multicolumn{2}{|l|}{ Risk factors } \\
\hline Current smoking, n (\%) & $125(36.7 \%)$ \\
\hline Hypertension, n (\%) & $120(35.3 \%)$ \\
\hline Dyslipidemia, n (\%) & $107(31.4 \%)$ \\
\hline Diabetes mellitus, n (\%) & $106(31.2 \%)$ \\
\hline Family history, n (\%) & $56(16.5 \%)$ \\
\hline \multicolumn{2}{|l|}{ Cardiac history } \\
\hline Prior MI, n (\%) & $13(3.8 \%)$ \\
\hline Prior CABG, n (\%) & $4(1.2 \%)$ \\
\hline Prior PCI, n (\%) & $15(4.4 \%)$ \\
\hline Prior Stroke, n (\%) & $2(0.6 \%)$ \\
\hline \multicolumn{2}{|l|}{ Clinical presentation } \\
\hline Stable angina, $\mathrm{n}(\%)$ & $130(38.2 \%)$ \\
\hline Unstable angina, n (\%) & $68(20.0 \%)$ \\
\hline STEMI, n (\%) & $56(16.5 \%)$ \\
\hline NSTEMI, n (\%) & $86(25.3 \%)$ \\
\hline
\end{tabular}

membranes and plaque tissues closed to injury site. Thus, everolimus in association with biodegradable polymer matrix is an effective combination which can significantly reduce smooth muscle cell proliferation without delayed healing or impaired endothelization [13]. This effectiveness of biodegradable polymer coated everolimus-eluting stents is evidenced in reports of meta-analysis comparing everolimus eluting stents directly with sirolimus-eluting stents [9] [14] [15]. It demonstrated significant superiority of everolimus-eluting stents with regards to stent thrombosis and repeat revascularization.

Moreover, many preclinical and clinical studies have demonstrated the effect of stent thickness and flexibility on vessel injury and degree of healing, with thinner strut leading to decreased incidence [16] [17]. Additionally, the chance of stent thrombosis increases with thicker struts due to presence of higher stent material in the vessel [18] [19].

Thus, the unique features of Everoflex coronary stent system, which involve everolimus as an immunosuppressive agent, biodegradable polymer and strut thickness as low as $60 \mu$ is a perfect combination which accounts for its optimum result. The preliminary results are favorable with only $0.3 \%$ chances of stent thrombosis and target lesion revascularization. Low incidence of stent thrombosis, which is a major concern, 
Table 2. Lesion and procedural characteristics.

\begin{tabular}{lc}
\hline Characteristics & $\begin{array}{c}\text { Patients, } \mathrm{n}=340 \\
\text { Lesions, } \mathrm{n}=395\end{array}$ \\
\hline Target vessel location & $1(0.3 \%)$ \\
Left main artery, $\mathrm{n}(\%)$ & $208(52.7 \%)$ \\
Left anterior descending artery, $\mathrm{n}(\%)$ & $80(20.3 \%)$ \\
Left circumflex artery, $\mathrm{n}(\%)$ & $106(26.8 \%)$ \\
Right coronary artery, $\mathrm{n}(\%)$ & \\
Lesion classification (ACC/AHA score) & \\
Type A, $\mathrm{n}(\%)$ & $49(12.4 \%)$ \\
Type B1, $\mathrm{n}(\%)$ & $68(17.2 \%)$ \\
Type B2, $\mathrm{n}(\%)$ & $68(17.2 \%)$ \\
Type C, $\mathrm{n}(\%)$ & $210(53.2 \%)$ \\
Disease severity & \\
Multivesssel disease, $\mathrm{n}(\%)$ & $197(57.9 \%)$ \\
Total occlusion, $\mathrm{n}(\%)$ & $61(15.4 \%)$ \\
Total number of stent, $\mathrm{n}$ & 447 \\
Number of stents per patient, mm (mean \pm SD) & $1.3 \pm 0.6$ \\
Number of stents per lesion, mm (mean \pm SD) & $1.1 \pm 0.4$ \\
Average stent length, mm (mean \pm SD) & $26.9 \pm 9.4$ \\
Average stent diameter, mm (mean \pm SD) & $2.9 \pm 0.3$ \\
\hline
\end{tabular}

Table 3. Clinical outcomes at 30 days follow-up.

\begin{tabular}{lc}
\hline Outcomes & 30 days follow-up \\
\hline Death, $\mathbf{n}(\%)$ & $4(1.2 \%)$ \\
Cardiac death, n (\%) & $4(1.2 \%)$ \\
Non-cardiac death, n (\%) & $0(0)$ \\
Myocardial infarction, $\mathbf{n}(\%)$ & $0(0)$ \\
Target lesion revascularization, $\mathbf{n}(\%)$ & $1(0.3 \%)$ \\
Target vessel revascularization, $\mathbf{n}(\%)$ & $0(0 \%)$ \\
Overall stent thrombosis, $\mathbf{n}(\%)$ & $1(0.3 \%)$ \\
Definite stent thrombosis, $\mathrm{n}(\%)$ & $1(0.3 \%)$ \\
Probable stent thrombosis, $\mathbf{n}(\%)$ & $0(0 \%)$ \\
Possible stent thrombosis, $\mathrm{n}(\%)$ & $0(0 \%)$ \\
Major adverse cardiac events, $\mathbf{n}(\%)$ & $5(1.5 \%)$ \\
\hline
\end{tabular}

has been reported with newer generation everolimus eluting stents [6]. This is in consistence with our study at 30-day follow-up. Moreover, one of the meta-analysis by Palmerini et al. demonstrated that everolimus-eluting stents with cobalt chromium platform and more thinner and biodegradable layer were associated with significantly lowered risk for definite ST as compared to bare metal stents(OR 0.35, 95\% CI 0.17 - 
0.69 ) and paclitaxel-eluting stents (OR 0.34, 95\% CI 0.19 - 0.62) [7]. However, the long term follow-up of our study will give better understanding of the benefits related to reduction in target lesion revascularization and late and very late stent thrombosis.

\section{Study Limitations}

The major limitation of the study is its retrospective "all-comers" design with minimum inclusion and exclusion criteria leading to inconsistencies and deviation in the outcomes. Moreover, follow-up time of enrolled patients is quite short. Long-term follow-up is needed to ensure further safety and clinical performance of the study stent.

\section{Conclusion}

The low incidence of MACE and stent thrombosis clearly depicts excellent safety and clinical performance of the Everoflex in unselected "real-world" patients with coronary artery disease.

\section{References}

[1] Kastrati, A., Mehilli, J., Pache, J., Kaiser, C., Valgimigli, M., Kelbæk, H., et al. (2007) Analysis of 14 Trials Comparing Sirolimus-Eluting Stents with Bare-Metal Stents. New England Journal of Medicine, 356, 1030-1039. https://doi.org/10.1056/NEJMoa067484

[2] Stettler, C., Allemann, S., Wandel, S., Kastrati, A., Morice, M.C., Schömig, A., et al. (2008) Drug Eluting and Bare Metal Stents in People with and without Diabetes: Collaborative Network Meta-Analysis. British Medical Journal, 337, a1331. https://doi.org/10.1136/bmj.a1331

[3] Camenzind, E., Steg, P.G. and Wijns, W. (2007) A Cause for Concern. Circulation, 115, 1440-1455. https://doi.org/10.1161/CIRCULATIONAHA.106.666800

[4] Wenaweser, P., Daemen, J., Zwahlen, M., van Domburg, R., Jüni, P., Vaina, S., et al. (2008) Incidence and Correlates of Drug-Eluting Stent Thrombosis in Routine Clinical Practice: 4-Year Results from a Large 2-Institutional Cohort Study. Journal of the American College of Cardiology, 52, 1134-1140. https://doi.org/10.1016/j.jacc.2008.07.006

[5] Stone, G.W., Midei, M., Newman, W., Sanz, M., Hermiller, J.B., Williams, J., et al. (2008) Comparison of an Everolimus-Eluting Stent and a Paclitaxel-Eluting Stent in Patients with Coronary Artery Disease: A Randomized Trial. JAMA, 299, 1903-1913. https://doi.org/10.1001/jama.299.16.1903

[6] Baber, U., Mehran, R., Sharma, S.K., Brar, S., Yu, J., Suh, J.-W., et al. (2011) Impact of the Everolimus-Eluting Stent on Stent Thrombosis: A Meta-Analysis of 13 Randomized Trials. Journal of the American College of Cardiology, 58, 1569-1577. https://doi.org/10.1016/j.jacc.2011.06.049

[7] Palmerini, T., Kirtane, A.J., Serruys, P.W., Smits, P.C., Kedhi, E., Kereiakes, D., et al. (2012) Stent Thrombosis with Everolimus-Eluting Stents Meta-Analysis of Comparative Randomized Controlled Trials. Circulation: Cardiovascular Interventions, 5, 357-364. https://doi.org/10.1161/circinterventions.111.967083

[8] Palmerini, T., Biondi-Zoccai, G., Della Riva, D., Stettler, C., Sangiorgi, D., D’Ascenzo, F., et al. (2012) Stent Thrombosis with Drug-Eluting and Bare-Metal Stents: Evidence from a Comprehensive Network Meta-Analysis. The Lancet, 379, 1393-1402.

https://doi.org/10.1016/S0140-6736(12)60324-9 
[9] de Waha, A., Cassese, S., Park, D.-W., Burzotta, F., Byrne, R.A., Tada, T., et al. (2012) Everolimus-Eluting versus Sirolimus-Eluting Stents: An Updated Meta-Analysis of Randomized Trials. Clinical Research in Cardiology, 101, 461-467. https://doi.org/10.1007/s00392-012-0414-8

[10] King, S.B., Smith, S.C., Hirshfeld, J.W., Jacobs, A.K., Morrison, D.A., Williams, D.O., et al. (2008) 2007 Focused Update of the ACC/AHA/SCAI 2005 Guideline Update for Percutaneous Coronary Intervention. A Report of the American College of Cardiology/American Heart Association Task Force on Practice Guidelines: 2007 Writing Group to Review New Evidence and Update the ACC/AHA/SCAI 2005 Guideline Update for Percutaneous Coronary Intervention, Writing on Behalf of the 2005 Writing Committee. Circulation, 117, 261-295. https://doi.org/10.1161/CIRCULATIONAHA.107.188208

[11] Grouve, E. and Kristensen, S. (2007) Stent Thrombosis: Definitions, Mechanisms and Prevention. E-Journal of Cardiology Practice, 32.

[12] Schuler, W., Sedrani, R., Cottens, S., Häberlin, B., Schulz, M., Schuurman, H.-J., et al. (1997) SDZ RAD, a New Rapamycin Derivative: Pharmacological Properties in Vitro and in Vivo. Transplantation, 64, 36-42. https://doi.org/10.1097/00007890-199707150-00008

[13] Grube, E., Sonoda, S., Ikeno, F., Honda, Y., Kar, S., Chan, C., et al. (2004) Six- and TwelveMonth Results from First Human Experience Using Everolimus-Eluting Stents with Bioabsorbable Polymer. Circulation, 109, 2168-2171. https://doi.org/10.1161/01.CIR.0000128850.84227.FD

[14] de Waha, A., Dibra, A., Byrne, R.A., Ndrepepa, G., Mehilli, J., Fusaro, M., et al. (2011) Everolimus-Eluting versus Sirolimus-Eluting Stents a Meta-Analysis of Randomized Trials. Circulation: Cardiovascular Interventions, 4, 371-377. https://doi.org/10.1161/circinterventions.111.963256

[15] Park, K.W., Kang, S.-H., Velders, M.A., Shin, D.-H., Hahn, S., Lim, W.-H., et al. (2013) Safety and Efficacy of Everolimus-Versus Sirolimus-Eluting Stents: A Systematic Review and Meta-Analysis of 11 Randomized Trials. American Heart Journal, 165, 241-250.

[16] Sullivan, T.M., Ainsworth, S.D., Langan, E.M., Taylor, S., Snyder, B., Cull, D., et al. (2002) Effect of Endovascular Stent Strut Geometry on Vascular Injury, Myointimal Hyperplasia, and Restenosis. Journal of Vascular Surgery, 36, 143-149. https://doi.org/10.1067/mva.2002.122878

[17] Hara, H., Nakamura, M., Palmaz, J.C. and Schwartz, R.S. (2006) Role of Stent Design and Coatings on Restenosis and Thrombosis. Advanced Drug Delivery Reviews, 58, 377-386. https://doi.org/10.1016/j.addr.2006.01.022

[18] Kastrati, A., Mehilli, J., Dirschinger, J., Dotzer, F., Schuhlen, H., Neumann, F.J., et al. (2001) Intracoronary Stenting and Angiographic Results: Strut Thickness Effect on Restenosis Outcome (ISAR-STEREO) Trial. Circulation, 103, 2816-2821. https://doi.org/10.1161/01.CIR.103.23.2816

[19] Briguori, C., Sarais, C., Pagnotta, P., Liistro, F., Montorfano, M., Chieffo, A., et al. (2002) In-Stent Restenosis in Small Coronary Arteries: Impact of Strut Thickness. Journal of the American College of Cardiology, 40, 403-409. https://doi.org/10.1016/S0735-1097(02)01989-7 
Submit or recommend next manuscript to SCIRP and we will provide best service for you:

Accepting pre-submission inquiries through Email, Facebook, LinkedIn, Twitter, etc. A wide selection of journals (inclusive of 9 subjects, more than 200 journals)

Providing 24-hour high-quality service

User-friendly online submission system

Fair and swift peer-review system

Efficient typesetting and proofreading procedure

Display of the result of downloads and visits, as well as the number of cited articles

Maximum dissemination of your research work

Submit your manuscript at: http://papersubmission.scirp.org/

Or contactwjcd@scirp.org 